Eixo Temático: Diretrizes Curriculares

\title{
ET-04-001 \\ A IMPORTÂNCIA DA BIOÉTICA NA FORMAÇÃO PROFISSIONAL DOS ALUNOS DO CURSO DE CIÊNCIAS BIOLÓGICAS
}

Jéssika Medeiros de Lucena, Danielle Siqueira Barreto De Oliveira, Paulo Fernando Guedes Pereira Montenegro, Eliete Lima de Paula Zaráte

Universidade Federal da Paraíba

http://dx.doi.org/10.21472/congrebio2016.et-04-001

\section{RESUMO}

A Bioética, constitui um importante aspecto na formação profissional de um biólogo. Foi proposto então, neste trabalho, investigar à maneira na qual os discentes do curso de graduação em Ciências Biológicas da Universidade Federal da Paraíba enxergam a ética, moral e a bioética na sua formação, e o que esperam aprender da disciplina, Bioética e legislação profissional, oferecida no curso. Ainda, foram investigados os conhecimentos dos alunos sobre a legislação profissão e institucional que regulamentam a sua formação inicial e continuada e, assim, gerar a possibilidade de diagnosticar e elaborar procedimentos metodológicos capazes de suprir as lacunas na formação dos estudantes. Para isso, foi realizada pesquisa quantitativaqualitativa com os licenciados e bacharéis, em que os dados foram coletados por meio de questionários e observação e, para sua observação foi utilizada a técnica análise de conteúdo. Desta forma, foram obtidos 70 questionários de alunos de três diferentes períodos que, apesar da maioria apontar concepções coerentes sobre os termos propostos, não souberam informar sobre a regulamentação da profissão de biólogo, mesmo vários tendo associado a ética com à legislação. A partir dos dados obtidos pode-se concluir que as concepções dos alunos sobre o tema não são errôneas. Além disso os alunos relacionam a bioética principalmente aos aspectos éticos e legais aplicados à biologia. E mais da metade dos alunos (65,7\%) não conhece os órgãos que regulamentam sua profissão. Ademais, os alunos reconhecem a importância da disciplina Bioética para a sua formação profissional.

Palavras-chave: Bioética; Legislação Profissional; Formação do Biólogo.

\section{INTRODUÇÃO}

Dois importantes aspectos na formação do profissional biólogo, envolvem o reconhecimento da normatização legal associada à sua profissão, e a capacidade de lidaradequadamente, com os dilemas éticos que venham a enfrentar em sua atuação.

Conforme expresso por Bittar (2009), a ética possui uma grande influência dentro da moral social, uma vez que permite uma reflexão crítica dos valores e dos costumes, tornando assim, fundamental a abordagem desse tema na graduação dos futuros profissionais.

A ética envolve a reflexão sobre as normas sociais, a liberdade de escolha sobre como segui-las e a responsabilidade dos riscos na composição dos resultados. Essas normas, ditadas pela Moral, visam orientar a conduta humana para uma boa convivência social, e quando são regulamentadas pelo estado, envolvendo obrigações e sanções, encontram-se na área do direito (Bittar, 2009). Ações vestidas de justiça e eticidade devem ponderar qualquer atitude humana, seja nas relações sociais ou nas ações profissionais, quando se tornam de fundamental importância para o sucesso na carreira (Gonçalves, 2010).

Segundo Bittar (2009), a Ética Profissional está vinculada à finalidade social, uma vez que as ações realizadas por um profissional durante a sua atuação poderão apresentar um 
impacto sobre os aspectos morais da sociedade, implicando em uma modificação direta ou indireta do ambiente, da conduta, ou da condição de vida das pessoas. Desta forma, o profissional deverá ajustar a sua ética pessoal as normas que norteiam o comportamento de sua respectiva categoria, em que a liberdade ética esbarra nas exigências da instituição que as controlam. O termo Bioética está amplamente associado às áreas da saúde e meio ambiente, e sua origem é atribuída a Van Rensselaer Potter, com a publicação dos artigos "Bioethics: The Science of Survival", em 1970, e "Bioethics: Bridge to the Future", em 1971, colocando a Bioética como uma entre a humanidade e a ciência com o futuro (Facco et al., 2010). Entretanto, Fritz Jahr já havia utilizado esse termo em 1927 para discutir a importância de o homem respeitar todo o ser vivo, essencialmente como um fim em si mesmo e tratá-los, sempre que possível como tal. Assim, a Bioética pode ser definida como o reconhecimento de obrigações éticas em relação a todas as formas de vidas existentes, e tanto as obras de Potter, quanto de Jahr procuraram mostrar que os valores éticos estão extremamente conectados a questões biológicas (GOLDIM, 2006).

Entretanto, conforme retratado por Facco et al. (2010), a bioética só teve seu reconhecimento na $33^{\mathrm{a}}$ Conferência Geral da UNESCO, em 2005, em Paris. Antes de um final satisfatório, sua construção sofreu alguns retrocessos, visto que foi muito limitada aos campos biomédico e biotecnológico, o que infelizmente, na visão da sociedade como um todo, ainda ocorre com bastante frequência. Devido à existência atual de muitas concepções diferentes e, em princípio, legítimas sobre a bioética, hoje podemos ver a expressão "bioética amplamente entendida” sendo utilizadas, por autores como Schramm (2002).

Dada a importância do conhecimento sobre bioética e sobre os aspectos legais relacionados à profissão do biólogo para uma atuação profissional socialmente responsável, acreditamos ser necessário investigar as concepções dos discentes sobre esses temas, visando nortear a sua abordagem na disciplina Bioética e legislação profissional ministrada para os cursos de Ciências Biológicas da Universidade Federal da Paraíba.

\section{OBJETIVOS}

Investigar as concepções dos discentes do curso de graduação em Ciências Biológicas da Universidade Federal da Paraíba sobre Ética, Moral e Bioética. Neste, também se buscou identificar os conhecimentos dos alunos a respeito da legislação profissional e institucional que estão diretamente ligas a sua formação profissional como biólogo e a importância da disciplina Bioética e Legislação Profissional para esta formação.

\section{METODOLOGIA}

Este estudo foi desenvolvido na Universidade Federal da Paraíba, com os alunos do Curso de Ciências Biológicas nas modalidades Licenciatura e Bacharelado, consistindo de uma pesquisa quantitativa-qualitativa.

Segundo Pasqualotti e Portella (2003), a pesquisa quantitativa tem como objeto de estudo os fatos naturais descritos, onde o uso de técnicas estatísticas pode levar à confirmação ou refutação das hipóteses previamente definidas. Em contrapartida, a pesquisa qualitativa tem como objeto de estudo o significado humano dos dados, permitindo sua melhor compreensão e explanação, levando o pesquisador a uma interpretação simultânea à apresentação dos resultados e à revisão das hipóteses.

Os dados foram coletados por meio de questionários e submetidos à técnica de análise de conteúdo (Bardin, 2009). Esta técnica exige uma codificação que abranja a representação do conteúdo ou sua expressão, e para isso se pode usar palavras, temas, contextos, relações, personagens, ou outras informações, até se chegar à categorização dos mesmos. 


\section{RESULTADOS E DISCUSSÃO}

Foram analisados 70 questionários, de alunos nos períodos 2014.2 / 2015.1 / 2015.2. Para as turmas da modalidade Licenciatura noturno e Bacharelado esse componente curricular é ofertado obrigatoriamente no $3^{\circ}$ período, e para a modalidade Licenciatura diurno, no $1^{\circ}$ período, e em todo os casos, não é pré-requisito para nenhuma outra disciplina no atual Programa Pedagógico Curricular do curso de Ciências Biológicas da Universidade Federal da Paraíba.

Quadro 1. Concepções prévias dos alunos do curso de Ciências Biológicas sobre Ética.

\begin{tabular}{|c|c|c|c|c|}
\hline & Categorias & Exemplos & & cias \\
\hline \multirow{8}{*}{ 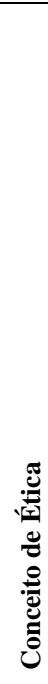 } & CONDUTA CORRETA & "É forma de agir, uma conduta ética." & 17 & $24 \%$ \\
\hline & EDUCAÇÃO SOCIAL & $\begin{array}{c}\text { "É a educação que temos para com as } \\
\text { pessoas da sociedade" }\end{array}$ & 17 & $24 \%$ \\
\hline & LEGISLAÇÃO & "É seu poder de seguir leis" & 16 & $23 \%$ \\
\hline & RESPEITO & "Respeito" & 7 & $10 \%$ \\
\hline & VALORES INDIVIDUAIS & $\begin{array}{l}\text { "Significa valores morais e bons } \\
\text { princípios" }\end{array}$ & 6 & $9 \%$ \\
\hline & $\begin{array}{l}\text { COMPORTAMENTO } \\
\text { PADRÃO }\end{array}$ & $\begin{array}{l}\text { "Seria uma maneira de determinado } \\
\text { padrão para uma determinada classe" }\end{array}$ & 3 & $4 \%$ \\
\hline & PRÁTICA ÉTICA & “é a prática de uma ética" & 1 & $2 \%$ \\
\hline & \multicolumn{2}{|l|}{ Não responderam } & 3 & $4 \%$ \\
\hline & \multicolumn{2}{|l|}{ Total } & 70 & $100 \%$ \\
\hline
\end{tabular}

O Quadro 1 resume os significados de ética para os alunos, divididos em sete categorias, com 71\% das citações concentradas em três delas: CONDUTA CORRETA (17 citações), EDUCAÇÃO SOCIAL (17 citações) e LEGISLAÇÃO (16 citações).

Assim, as concepções dos alunos sobre o tema não são errôneas e focam em diversos aspectos da ética, principalmente na conduta correta e educação social. Chama atenção, ainda, o fato de que aproximadamente $24 \%$ dos alunos relacionaram a ética com aspectos legais. Segundo Santos (1997, p. 12), a ética faz referência a um "conjunto de hábitos e costumes, efetivamente vivenciados por um grupo humano", enquanto que a lei faz referências a "acordos de caráter obrigatório, estabelecidos entre pessoas de um grupo, para garantir justiça mínima, ou direitos mínimos de ser”. Embora a ética e a lei abordem de maneiras diferentes a relação do indivíduo com as regras sociais estabelecidas, elas se encontram relacionadas.

Segundo o Dicionário Aurélio Buarque de Holanda, Ética é o estudo dos juízos de apreciação que se referem à conduta humana susceptível de qualificação do ponto de vista do bem e do mal, seja relativamente à determinada sociedade, seja de modo absoluto. Ou seja, a ética está relacionada a uma conduta correta, especifica, dentro da qual está inserida uma educação social. A educação social começa no ensino básico a partir do ensino de ética, proposto pelas Diretrizes Curriculares Nacionais (DCNs) distribuído transversalmente nas disciplinas básicas. A abordagem da ética é voltada para a formação do cidadão como um ser social, e se estende até o ensino superior por meio da Bioética. Segundo o Parecer CNE/CES 1.301/2001, que aprova as DCNs para cursos de Ciências Biológicas, os Fundamentos Filosóficos Sociais constam como um dos conteúdos básicos a serem trabalhados como um 
suporte a formação profissional do cidadão permitindo que reflitam sobre as suas condutas éticas.

Sobre as concepções de moral distribuídas em oito categorias no Quadro 02, quatro delas, VALORES INDIVIDUAIS (14 citações), LEGISLAÇÃO (13 citações), VISÃO SOCIAL (12 citações) e CONDUTA CORRETA (12 citações), apresentaram maiores números de citações contabilizando juntas 68,5\%.

Quadro 2. Concepções prévias dos alunos do curso de Ciências Biológicas sobre Moral.

\begin{tabular}{|c|c|c|c|c|}
\hline & Categorias & Exemplos & \multicolumn{2}{|c|}{ Frequências } \\
\hline \multirow{8}{*}{ 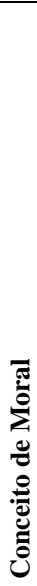 } & VALORES INDIVIDUAIS & $\begin{array}{l}\text { "É um valor pessoal no qual algumas } \\
\text { pessoas tem diferentes perspectivas" }\end{array}$ & 14 & $20 \%$ \\
\hline & LEGISLAÇÃO & "Conjunto de regras" & 13 & $18,5 \%$ \\
\hline & VISÃO SOCIAL & $\begin{array}{c}\text { "A forma como a sociedade enxerga } \\
\text { as posturas alheias" }\end{array}$ & 12 & $17 \%$ \\
\hline & CONDUTA CORRETA & $\begin{array}{l}\text { "Uma conduta correta aplicada a um } \\
\text { grupo especifico de indivíduos.” }\end{array}$ & 9 & $13 \%$ \\
\hline & RESPEITO & $\begin{array}{c}\text { "Atos que respeitam o senso comum e } \\
\text { os ideias de um grupo, sociedade, } \\
\text { etc.." }\end{array}$ & 3 & $4 \%$ \\
\hline & ATITUDE ÉTICA & $\begin{array}{l}\text { "Parece com ética, forma de agir, } \\
\text { atitude ética" }\end{array}$ & 2 & $3 \%$ \\
\hline & FILOSOFIA & $\begin{array}{l}\text { "Um ramo da filosofia que define o } \\
\text { que é certo e errado" }\end{array}$ & 1 & $1,4 \%$ \\
\hline & \multicolumn{2}{|l|}{ Não responderam } & 16 & $23 \%$ \\
\hline & \multicolumn{2}{|l|}{ Total } & 70 & $100 \%$ \\
\hline
\end{tabular}

É importante lembrar que a filosofia distingue os termos Ética e Moral. Segundo Coelho (2007), a Moral tem a ver com o “justo”, e está relacionado as regras que fixam condições justas de convivência com respeito e liberdade, onde cada indivíduo vive de acordo com a sua moral.

Um dado ao qual desperta a atenção é para os números de alunos que não responderam essa questão, totalizando $23 \%$ com (16 citações), que se comparada as demais categorias individuais essa supera todas elas.

Os conhecimentos prévios dos alunos sobre o tema Bioética estão relacionados no Quadro 03. Foram identificadas 08 categorias e duas delas contém 67\% das citações: 24 alunos $(34,2 \%)$ afirmaram que Bioética é um conjunto de regras que norteiam a profissão do biólogo, e cerca de 23 (32,8\%) afirmam que a Bioética está relacionada com a ética voltada para o curso de biologia. Apesar de aproximadamente 33\% dos alunos relacionarem a bioética aos aspectos éticos aplicados à biologia, uma das concepções prevalentes sobre esse tema envolve aspectos legais da profissão (34,2\% dos alunos). Esta concepção reflete a ideia de ética relacionada à legislação, conforme relacionado no Quadro 01, e mostra a necessidade de uma melhor abordagem da distinção e relação entre esses dois aspectos nas aulas da disciplina de Bioética e Legislação Profissional. 
Quadro 3. Concepções prévias dos alunos do curso de Ciências Biológicas sobre Bioética.

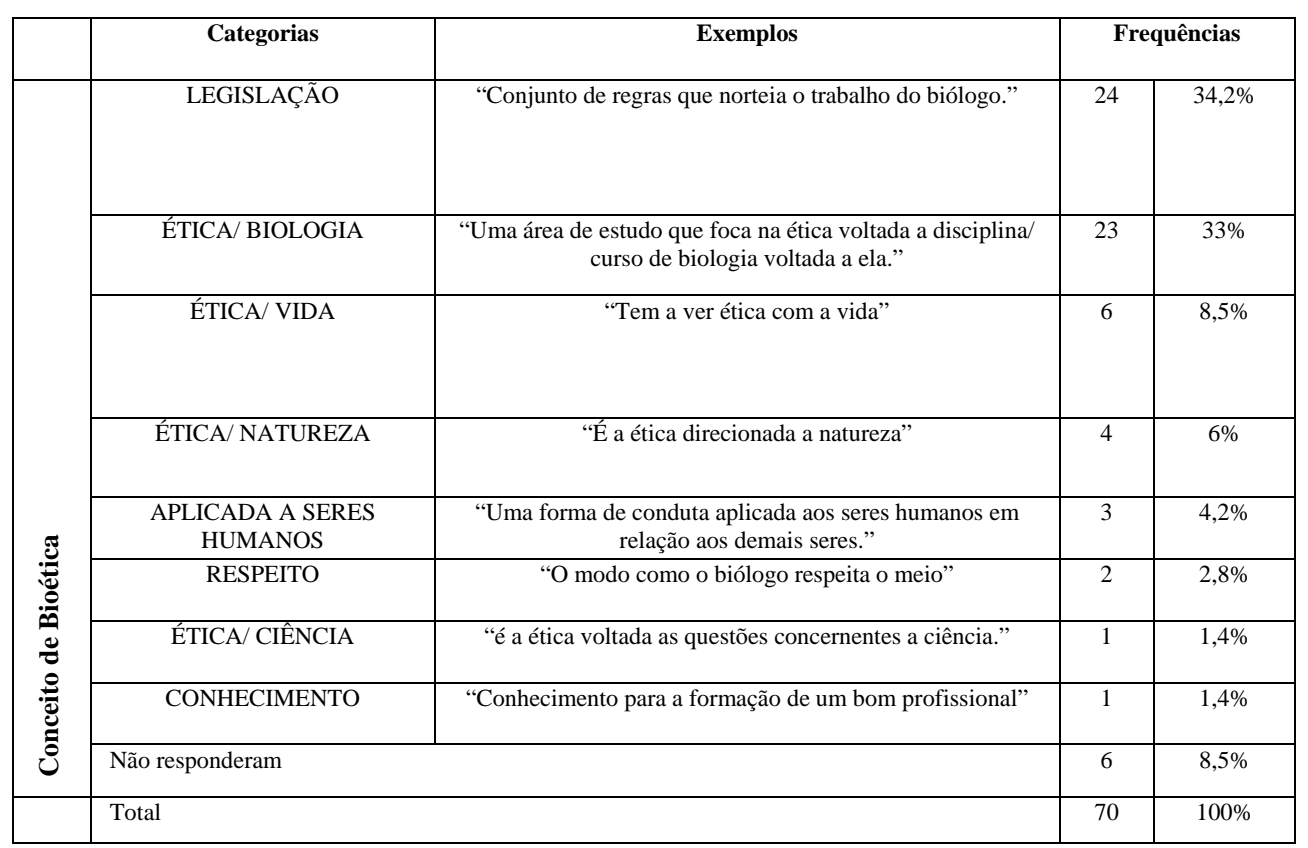

Nesse trabalho, também buscou-se investigar quais eram os conhecimentos dos alunos sobre a regulamentação do curso e profissional, e quais os órgãos responsáveis pela regulamentação da profissão. Mais da metade dos alunos $(65,7 \%)$ não conhece os órgãos que regulamentam sua profissão; os outros 24,3\% que disseam ter conhecimento citaram o CRBio e o IBAMA, com apenas quatro citações para o CFBio.

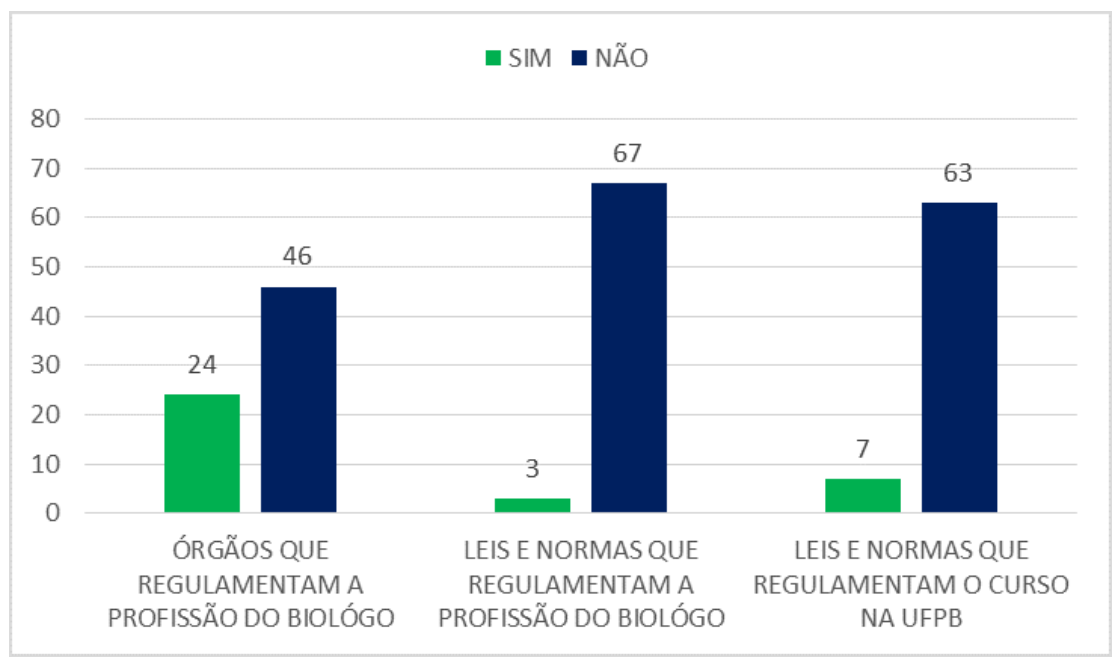

Gráfico 1. Conhecimentos prévios dos alunos sobre as leis que regem o curso,a profissão do biólogo, e os órgãos que regulamentam e fiscalização a profissão.

Questionados sobre o conhecimento das leis e normas que regulamentam seu curso na UFPB, 63 alunos (90\%) disseram desconhecê-las. Os poucos que citaram conhecer referiram-se apenas à quantidade de faltas nas disciplinas que podem ter por semestre.

Por fim foi questionado aos alunos sobre a importância da disciplina de Bioética e Legislação Profissional para a formação do Biólogo (Quadro 04). Observa-se que a bioética merece um destaque na formação profissional do biólogo, pois 84\% dos alunos apresentam em 
três categorias a relação das condutas éticas com o desenvolvimento prático de seu trabalho a partir de embasamentos legais.

Quadro 4. A importância e contribuição profissional da Bioética na formação do Biólogo.

\begin{tabular}{|c|c|c|c|c|c|}
\hline & Categorias & Componentes & Exemplos & & encias \\
\hline \multirow{6}{*}{ 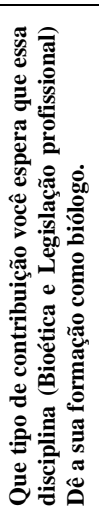 } & $\begin{array}{c}\text { CIENTE DAS } \\
\text { NORMAS E LEIS }\end{array}$ & Informação & $\begin{array}{c}\text { "Espero que me dê a instrução necessária para exerce a } \\
\text { minha profissão dentro das leis e tendo consciência } \\
\text { daquilo que é o direito e dever do biólogo." }\end{array}$ & 27 & $38,5 \%$ \\
\hline & $\begin{array}{l}\text { COMPLEMENTAÇÃO } \\
\text { NA FORMAÇÃO }\end{array}$ & Complemento & $\begin{array}{l}\text { "Espero que incremente a minha formação e me torne } \\
\text { um bom profissional" }\end{array}$ & 21 & $30 \%$ \\
\hline & CONDUTAS ÉTICAS & Ética/ Legislação & $\begin{array}{l}\text { "A disciplina tem como finalidade orientar o futuro } \\
\text { biólogo a proceder no seu trabalho com ética e } \\
\text { seguindo a legislação profissional.” }\end{array}$ & 11 & $15,7 \%$ \\
\hline & CONHECIMENTO & Experiência & "Conhecimento para a formação de um profissional." & 2 & $2,8 \%$ \\
\hline & RESPEITO & Conduta & "Respeito ao meio ambiente" & 1 & $1,4 \%$ \\
\hline & \multicolumn{3}{|l|}{ Não responderam } & 8 & $11,4 \%$ \\
\hline & \multicolumn{3}{|l|}{ Total } & 70 & $100 \%$ \\
\hline
\end{tabular}

Alguns teóricos como Azevedo (1998), Comstock e Rosa (2004) criticam o isolamento da Bioética nas disciplinas do curso de formação. Segundo AZEVEDO (1998), devido à amplitude do tema e às suas dimensões de aplicabilidade, "a Bioética lida com saberes na encruzilhada de várias disciplinas, sugerindo uma concepção interdisciplinar ou mesmo transdisciplinar para seu ensino" De acordo com esse autor, os alunos "Somente estarão preparados para o exercício profissional se, ao lado de competente formação técnica, também tiverem sido treinados para o reconhecimento de conflitos éticos, análise crítica de suas implicações, uso de senso de responsabilidade e obrigação moral ao tomar decisões [...]”. "A partir dos avanços tecnocientificos, a Bioética surge como forma de alertar a sociedade sobre os riscos do seu avanço, impondo-a limites éticos e contribuindo, assim, para atitudes mais conscientes ante os desafios trazidos pelas novas descobertas.” (DÓRIA E MOREIRA, 2011).

\section{CONCLUSÕES}

A partir dos dados obtidos pode-se concluir que:

1. As concepções dos alunos sobre o tema não são errôneas e focam principalmente na conduta correta, educação social e aspectos legais.

2. Os alunos relacionam a bioética principalmente aos aspectos éticos aplicados à biologia e aos aspectos legais da profissão. profissão.

3. Mais da metade dos alunos $(65,7 \%)$ não conhece os órgãos que regulamentam sua na UFPB.

4. A maioria dos alunos (90\%) desconhece as leis e normas que regulamentam seu curso

5. Os alunos reconhecem a importância da disciplina Bioética para a sua formação profissional. 


\section{REFERÊNCIAS}

AZEVEDO, E. E. S. Ensino da Bioética: um desafio transdisciplinar. São Paulo: Interface, 1998.

BARDIN, L. Análise de conteúdo. Lisboa: Edições 70, 2009.

COELHO, A. Aqui tem filosofia sim. Filosofia Moral: Ética e Moral. Disponível em: $<$ http://aquitemfilosofiasim.blogspot.com.br/2007/11/filosofia-moral-tica-e-moral.html>.

Acesso em: 30 de abr.2016.

CONSELHO NACIONAL DE EDUCAÇÃO. Parecer CNE/CES n ${ }^{\circ}$ 1.301/2001, de 4 de dezembro de 2001. Aprova as diretrizes curriculares nacionais do curso de graduação em ciências biológicas. Diário Oficial da União, Brasília, DF, Seção 1, p.25, 07 dez. 2001.

DÓRIA, T. A. F.; MOREIRA, L. M. A. A bioética na formação do biólogo: um desafio contemporâneo. Revista Entre Ideias: Educação, Cultura e Sociedade, n. 20, p. 99-122, 2011.

FACCO, F. A.; SCHNAIDER, T. B.; SILVA, J. V. A Bioética: histórico e princípios. Enciclopédia Biosfera, v. 6, n. 11, p. 1-11, 2010. Disponível em: $<$ http://www.conhecer.org.br/enciclop/2010c/a bioetica.pdf>. Acesso em: 30 de abr. 2016.

GONÇALVES, M.; DAROSSI, M.; STACCIARINI, S. Ética e Direito na convivência social: breve análise sobre o Código de Ética do Advogado. Revista da Unifebe, v. 1, p. 157-168, 2010. Disponível em: <https://www.unifebe.edu.br/revistadaunifebe/2010/artigo005.pdf>. Acesso em: 30 de abr. 2016.

GOLDIM, J. R. Bioética - origens e complexidade. Rev HCPA, 2006.

PASQUALOTTI, A.; PORTELLA, M. R. Quantitativo-qualitativo: o que precisamos saber sobre os métodos?. Universidade de Passo Fundo. Faculdade de Educação, [2003?]. Disponível em: <http://usuarios.upf.br/ pasqualotti/quantitativo_ qualitativo.ppt>. Acesso em: 26 abr. 2016.

SANTOS, F. A. Ethics and irony: the manager's predicament. Porto Alegre, MS/PPGA, 1997. (Apostila de Ética e Dinâmica da Sociedade).

SCHRAMM, F. R. A Bioética, seu desenvolvimento e importância para as Ciências da Vida e da Saúde. Revista Brasileira de Cancerologia, v. 48, n. 4, p. 609-615, 2002. Disponível em: <http://www.inca.gov.br/rbc/n_48/v04/pdf/opiniao.pdf>. Acesso em: 26 abr. 2016. 